\title{
Effect of an electronic nicotine delivery device (e-Cigarette) on smoking reduction and cessation: a prospective 6-month pilot study
}

\author{
Riccardo Polosa ${ }^{1,2^{*}}$, Pasquale Caponnetto ${ }^{1,2}$, Jaymin B Morjaria ${ }^{3}$, Gabriella Papale ${ }^{1,2}$, Davide Campagna ${ }^{1,2}$ and \\ Cristina Russo ${ }^{1,2}$
}

\begin{abstract}
Background: Cigarette smoking is a tough addiction to break. Therefore, improved approaches to smoking cessation are necessary. The electronic-cigarette (e-Cigarette), a battery-powered electronic nicotine delivery device (ENDD) resembling a cigarette, may help smokers to remain abstinent during their quit attempt or to reduce cigarette consumption. Efficacy and safety of these devices in long-term smoking cessation and/or smoking reduction studies have never been investigated.
\end{abstract}

Methods: In this prospective proof-of-concept study we monitored possible modifications in smoking habits of 40 regular smokers (unwilling to quit) experimenting the 'Categoria' e-Cigarette with a focus on smoking reduction and smoking abstinence. Study participants were invited to attend a total of five study visits: at baseline, week-4, week-8, week-12 and week-24. Product use, number of cigarettes smoked, and exhaled carbon monoxide (eCO) levels were measured at each visit. Smoking reduction and abstinence rates were calculated. Adverse events and product preferences were also reviewed.

Results: Sustained 50\% reduction in the number of cig/day at week-24 was shown in 13/40(32.5\%) participants; their median of 25 cigs/day decreasing to 6 cigs/day $(p<0.001$ ). Sustained $80 \%$ reduction was shown in $5 / 40$ (12.5\%) participants; their median of 30 cigs/day decreasing to 3 cigs/day $(p=0.043$ ). Sustained smoking abstinence at week-24 was observed in 9/40(22.5\%) participants, with 6/9 still using the e-Cigarette by the end of the study. Combined sustained 50\% reduction and smoking abstinence was shown in 22/40 (55\%) participants, with an overall $88 \%$ fall in cigs/day. Mouth (20.6\%) and throat (32.4\%) irritation, and dry cough (32.4\%) were common, but diminished substantially by week-24. Overall, 2 to 3 cartridges/day were used throughout the study. Participants' perception and acceptance of the product was good.

Conclusion: The use of e-Cigarette substantially decreased cigarette consumption without causing significant side effects in smokers not intending to quit (http://ClinicalTrials.gov number NCT01195597).

\section{Background}

With well over one billion smokers' worldwide, cigarette smoking is a global epidemic that poses a substantial health burden and costs [1]. This is because cigarette smoke harms several organ systems of the human body, thus causing a broad range of diseases, many of which are fatal $[2,3]$. The risk of serious disease diminishes

\footnotetext{
* Correspondence: polosa@unict.it

'Centro per la Prevenzione e Cura del Tabagismo (CPCT), Azienda Ospedaliero-Universitaria "Policlinico-Vittorio Emanuele", Università di Catania, Catania, Italy

Full list of author information is available at the end of the article
}

rapidly after quitting and life-long abstinence is known to reduce the risk of lung cancer, heart disease, strokes, chronic lung disease and other cancers $[4,5]$.

Although evidence-based recommendations indicate that smoking cessation programs are useful in helping smokers to quit [6], smoking is a very difficult addiction to break. It has been shown that approximately $80 \%$ of smokers who attempt to quit on their own, relapse within the first month of abstinence and only about 3$5 \%$ remain abstinent at 6 months [7]. Although there is little doubt that currently-marketed smoking cessation

\section{Biomed Central}


products increase the chance of committed smokers to stop smoking, they reportedly lack high levels of efficacy, especially in the real life setting [8]. Although this is known to reflect the chronic relapsing nature of tobacco dependence, the need for novel and effective approaches to smoking cessation interventions is beyond doubt.

The electronic-cigarette (e-Cigarette) is a battery-powered electronic nicotine delivery device (ENDD) resembling a cigarette designed for the purpose of nicotine delivery, where no tobacco or combustion is necessary for its operation [9] (Figure 1). Consequently, this product may be considered as a lower risk substitute for factory-made cigarettes. In addition, people report buying them to help quit smoking, to reduce cigarette consumption and to relieve tobacco withdrawal symptoms due to workplace smoking restrictions [10]. Besides delivering nicotine, e-Cigarettes may also provide a coping mechanism for conditioned smoking cues by replacing some of the rituals associated with smoking gestures (e. g. hand-to-mouth action of smoking). For this reason, eCigarettes may help smokers to remain abstinent during their quit attempt or to reduce cigarette consumption. A recent internet survey on the satisfaction of e-Cigarette use has reported that the device helped in smoking abstinence and improved smoking-related symptoms [11]. Under acute experimental conditions, two marketed electronic cigarette brands suppressed tobacco abstinence symptom ratings without leading to measurable levels of nicotine or CO in the exhaled breath [12]. The e-Cigarette is a very hot topic that has generated considerable global debate with authorities wanting to ban it or at least regulate it. Consequently, a formal demonstration supporting the efficacy and safety of these devices in smoking cessation and/or smoking reduction studies would be of utmost importance.

With this in mind, we designed a prospective proofof-concept study to monitor possible modifications in the smoking habits of a group of well characterized regular smokers experimenting the most popular marketed e-Cigarette in Italy ('Categoria'; Arbi Group Srl, Milano, Italy) focusing on smoking reduction and smoking abstinence. We also monitored adverse events and measured participants' perception and acceptance of the product.

\section{Methods \\ Participants}

Healthy smokers 18-60 years old, smoking $\geq 15$ factorymade cigarettes per day (cig/day) for at least the past 10 years and not currently attempting to quit smoking or wishing to do so in the next 30 days were recruited from the local Hospital staff in Catania, Italy. None of the participants reported a history of alcohol and illicit drug use, major depression or other psychiatric conditions. We also excluded subjects who reported recent myocardial infarction, angina pectoris, high blood pressure (BP > $140 \mathrm{mmHg}$ systolic and/or $90 \mathrm{mmHg}$ diastolic), diabetes mellitus, severe allergies, poorly controlled asthma or other airways diseases. The study protocol was discussed with the Chair of the local institutional ERB (Comitato Etico Azienda Vittorio Emanuele) in February 2010. In consideration of the fact that e-cigarette use is a widespread phenomenon in Italy, that many e-cigarette users are enjoying them as consumer goods, that this type of product is not regulated as a drug or a drug device in Italy (end users can buy e-cig almost

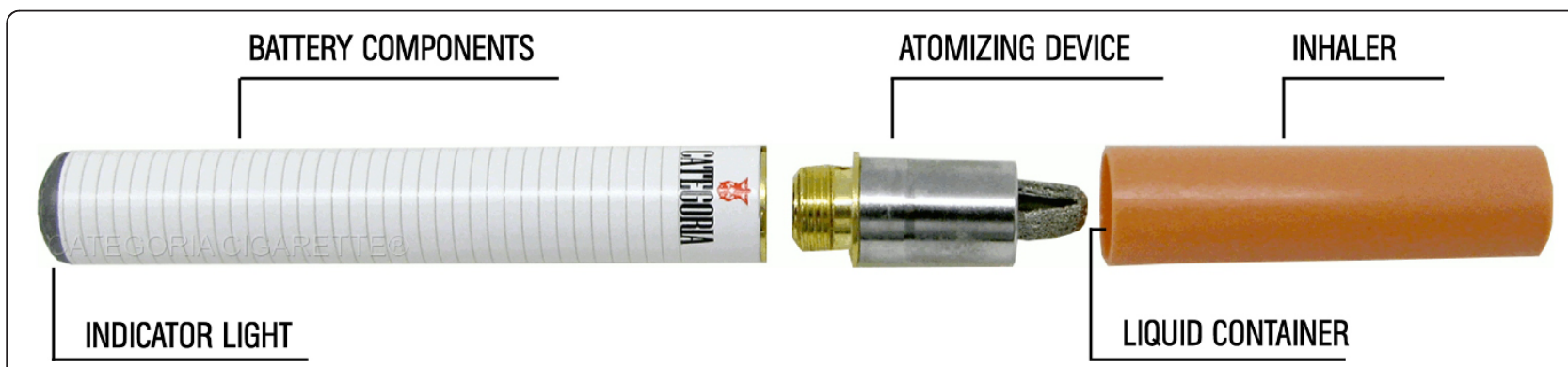

Figure 1 Structure of the 'Categoria' electronic-cigarette (e-Cigarette). The e-Cigarette is a battery-powered electronic nicotine delivery device (ENDD) resembling a cigarette designed for the purpose of providing inhaled doses of nicotine by way of a vaporized solution to the respiratory system. This device provides a flavor and physical sensation similar to that of inhaled tobacco smoke, while no smoke or combustion is actually involved in its operation. It is composed of the following key components: (1) the inhaler - also known as 'cartridge' (a disposable non-refillable plastic mouthpiece - resembling a tobacco cigarette's filter - which contains an absorbent material that is saturated with a liquid solution containing nicotine); (2) the atomizing device (the heating element that vaporizes the liquid in the mouthpiece and generates the mist with each puff); (3) the battery component (the body of the device - resembling a tobacco cigarette - which houses a lithium-ion re-chargeable battery to power the atomizer). The body of the device also houses an electronic airflow sensor to automatically activate the heating element upon inhalation and to light up a red LED indicator to signal activation of the device with each puff. Each pre-filled 'Original' cartridges used in this study contains nicotine (7.25 mg/cartridge) dissolved in propylene glycol (233.7 mg/cartridge) and vegetable glycerin (64.0 mg/cartridge) [details can be found at: http://www.liaf-onlus.org/public/allegati/categoria1b.pdf]. 
anywhere - internet, tobacconists, pharmacies, restaurants, and shops), and that only healthy smokers not willing to quit smoking would participate, it was felt that the study fulfilled the criteria of an observational naturalistic investigation and was exempt from the requirement from ethical approval. Participants gave written informed consent prior to participation in the study.

\section{Study Design and Baseline Measures}

Eligible participants were invited to use an ENDD ('Categoria' e-Cigarette, Arbi Group Srl, Milano, Italy) and were followed up prospectively for 6 months. They attended a total of five study visits at our smoking cessation clinic (Centro per la Prevenzione e Cura del Tabagismo (CPCT), Università di Catania, Italy): a baseline visit and four follow-up visits, (at week-4, week-8, week12 and week-24) (Figure 2).

At baseline (study visit 1), basic demographic and a detailed smoking history were taken and individual pack-years (pack/yrs) calculated together with scoring of their level of nicotine dependence by means of Fagerstrom Test of Nicotine Dependence (FTND) questionnaire [13]. Subjective ratings of depression were assessed with the Beck Depression Inventory (BDI) [14]. Additionally, levels of carbon monoxide in exhaled breath (eCO) were measured using a portable device (Micro CO, Micro Medical Ltd, UK). Participants were given a free e-Cigarette kit containing two rechargeable batteries, a charger, and two atomizers and instructed on how to charge, activate and use the e-Cigarette. Key troubleshooting were addressed and phone numbers were supplied for both technical and medical assistance. A full 4-weeks supply of $7.4 \mathrm{mg}$ nicotine cartridges ("Original" cartridges; Arbi Group Srl, Milano, Italy) was also provided and participants were trained on how to load them onto the e-Cigarette's atomizer. Random checks confirmed that the nicotine content per cartridge was 7,25 mg. Detailed toxicology and nicotine content analyses of "Original" cartridges had been carried in a laboratory certified by the Italian Institute of Health and can be found at: http://www.liaf-onlus.org/public/allegati/categoria1b.pdf

Participants were permitted to use the study product ad libitum throughout the day (up to a maximum of 4 cartridges per day, as recommended by the manufacturer) in the anticipation of reducing the number of cig/ day smoked, and to fill a 4-weeks' study diary recording product use, number of any tobacco cigarettes smoked, and adverse events.

Participants were invited to came back at week-4 (study visit 2), week-8 (study visit 3), and week-12 (visit 4), a) to receive further free supply of nicotine cartridges together with the study diaries for the residual study periods, b) to record their eCO levels, and c) to give back completed study diaries and unused study products.

Study participants attended a final follow-up visit at week-24 (study visit 5) to report product use (cartridges/day) and the number of any tobacco cigarettes smoked (from which smoking reduction and smoking abstinence could be calculated), to re-check eCO levels and to rate the degree of usefulness of the study product. In particular, participants were asked to rate their level of satisfaction with the products compared to their usual cigarettes using a visual analogue scale (VAS) from 0 to 10 points $(0=$ being 'completely unsatisfied', 10 being = 'fully satisfied'); on the same scale, they also rated helpfulness (in keeping them from smoking) and whether they would recommend it to a friend who wanted to stop/reduce smoking. Adverse events were obtained from their study diaries.

Given the observational nature of this study, no emphasis on encouragement, motivation and reward for the smoking cessation effort were provided since this study was intended to monitor the case of a smoker (unwilling to quit) trying out an unconventional nicotine delivery device in a real world setting. Although participants were allowed to smoke their own brand of cigarette as they wished, smoking cessation services were provided to those who would spontaneously ask for assistance with quitting. These subjects were excluded from the study protocol.

\section{Study outcome measures}

The primary efficacy measure was sustained $50 \%$ reduction in the number of cig/day at week-24 from baseline (reducers) [15]; defined as sustained self-reported 50\% reduction in the number of cig/day compared to baseline for the 30 days period prior to week-24 study visit (eCO levels were measured to verify smoking status and confirm a reduction compared to baseline).

A secondary efficacy measure of the study was sustained $80 \%$ reduction in the number of cig/day at week24 from baseline (heavy reducers); defined as sustained self-reported $80 \%$ reduction in the number of cig/day compared to baseline for the 30 days period prior to week-24 study visit (eCO levels were measured to verify smoking status and confirm a reduction compared to baseline).

An additional secondary efficacy measure of the study was sustained smoking abstinence at week-24 (quitters); defined as complete self-reported abstinence from tobacco smoking (not even a puff) for the 30 days period prior to week-24 study visit (eCO levels were measured to objectively verify smoking status with an eCO concentration of $\leq 10 \mathrm{ppm}$ ). 


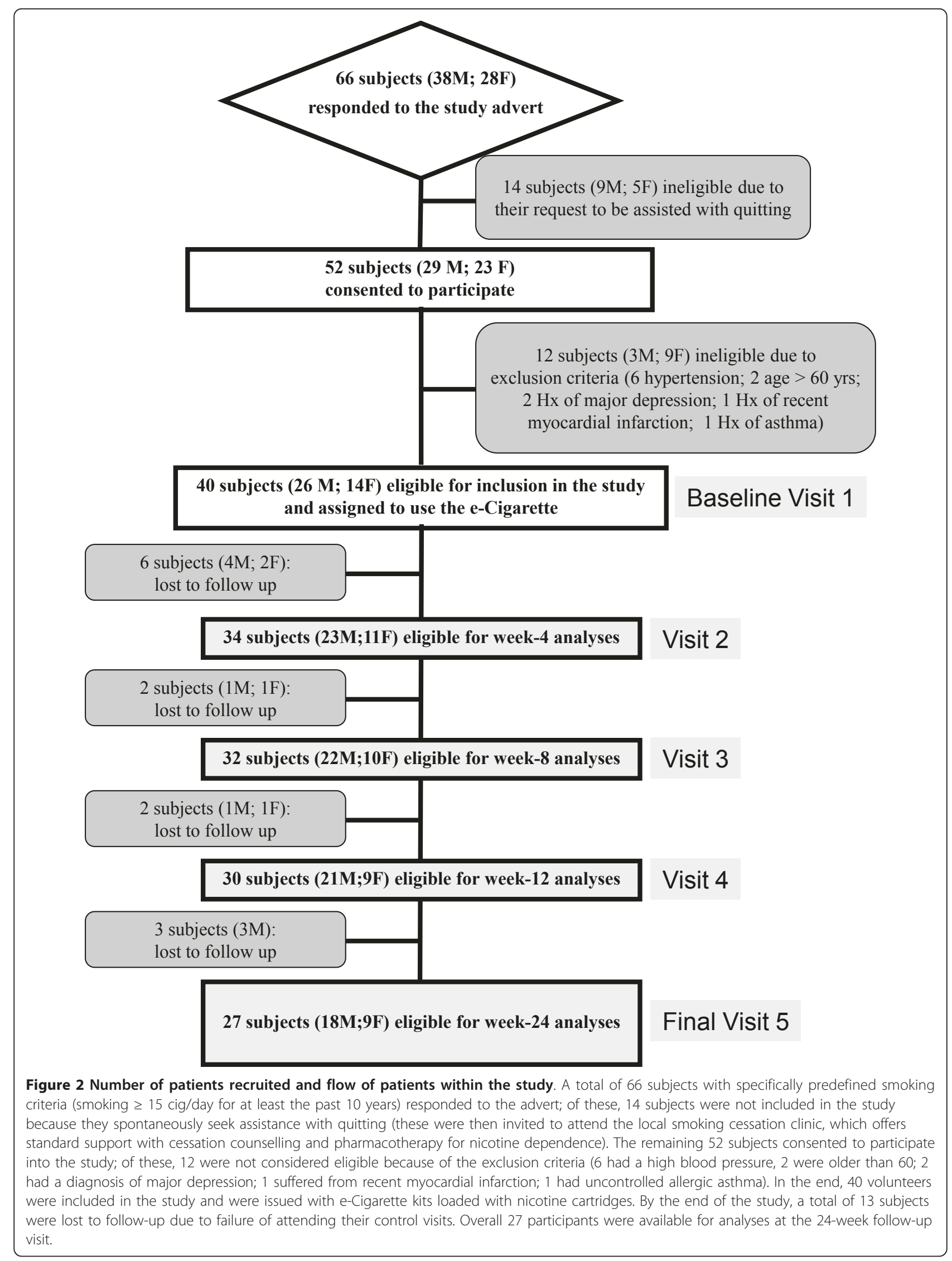


Those smokers who failed to meet the above criteria at the final week-24 follow-up visit (study visit 5) were categorized as reduction/cessation failures (failures).

\section{Statistical Analyses}

This was a proof-of-concept pilot study, the first of its kind, hence no previous data could be used for power calculation. However, using our previous experience in smoking cessation studies, we estimated that a sample of 40 subjects would have been adequate to acquire quit/reduction rates from $70-75 \%$ of the subjects enrolled [16]. Primary and secondary outcome measures were computed by including all enrolled participants assuming that all those individuals who were lost to follow-up are classified as failures (intention-to-treat analysis). The changes from baseline (study visit 1) in number of cig/day and in eCO levels were compared with data recorded at subsequent follow-up visits using Wilcoxon Signed rank test as these data were non-parametric. Parametric and non-parametric data were expressed as mean $( \pm$ SD) and median (interquartile range (IQR)) respectively. Correlations were calculated using Spearman's Rho Correlation. Statistical methods were 2 -tailed, and $\mathrm{P}$ values of $<0.05$ were considered significant.

\section{Results}

\section{Participant characteristics}

After excluding for the study exclusion criteria, a total of 40 (M 26; F 14; mean ( \pm SD) age of 42.9 ( \pm 8.8 ) years) regular smokers (mean $( \pm$ SD) pack/yrs of 34.9
$( \pm 14.7))$ consented to participate and were included in the study (Table 1; Figure 2). Twenty-seven (67.5\%) completed all study visits and returned for their final follow-up visit at week-24. Baseline characteristics of those who were lost to follow-up were not significantly different from participants who completed the study.

\section{Outcome measures}

Participants' smoking status at baseline and at 24-week is shown on Table 2. Taking the whole cohort of participants $(\mathrm{n}=40)$, an overall $80 \%$ reduction in median cig/ day use from 25 to 5 was observed by the end of the study $(\mathrm{p}<0.001)$. Sustained $50 \%$ reduction in the number of cig/day at week-24 was shown in 13/40 (32.5\%) participants, with a median of $25 \mathrm{cig} /$ day (IQR 20, 30) decreasing significantly to 6 cig/day (IQR 5, 6) (p < $0.001)$. Of these tobacco smoke reducers, five $(12.5 \%)$ could be classified as sustained heavy reducers (at least $80 \%$ reduction in the number of cig/day) at week- 24 . They had a median consumption of 30 cig/day (IQR 25, $35)$ at baseline, decreasing significantly to $3 \mathrm{cig} /$ day $($ IQR 3, 6) $(\mathrm{p}=0.043)$. There were $9 / 40(22.5 \%)$ quitters, with $6 / 9$ still using the e-Cigarette by the end of the study. Overall, combined sustained $50 \%$ reduction and smoking abstinence was shown in 22/40 (55\%) participants, with a median of 25 cig/day (IQR 20,30) decreasing significantly to $3 \mathrm{cig} /$ day (IQR 0,6$)(\mathrm{p}<0.001)$, which is equivalent to an overall $88 \%$ reduction. Details of mean cigarette use and eCO levels throughout the study is shown in Figure 3 and 4.

\section{Table 1 Patient Demographics}

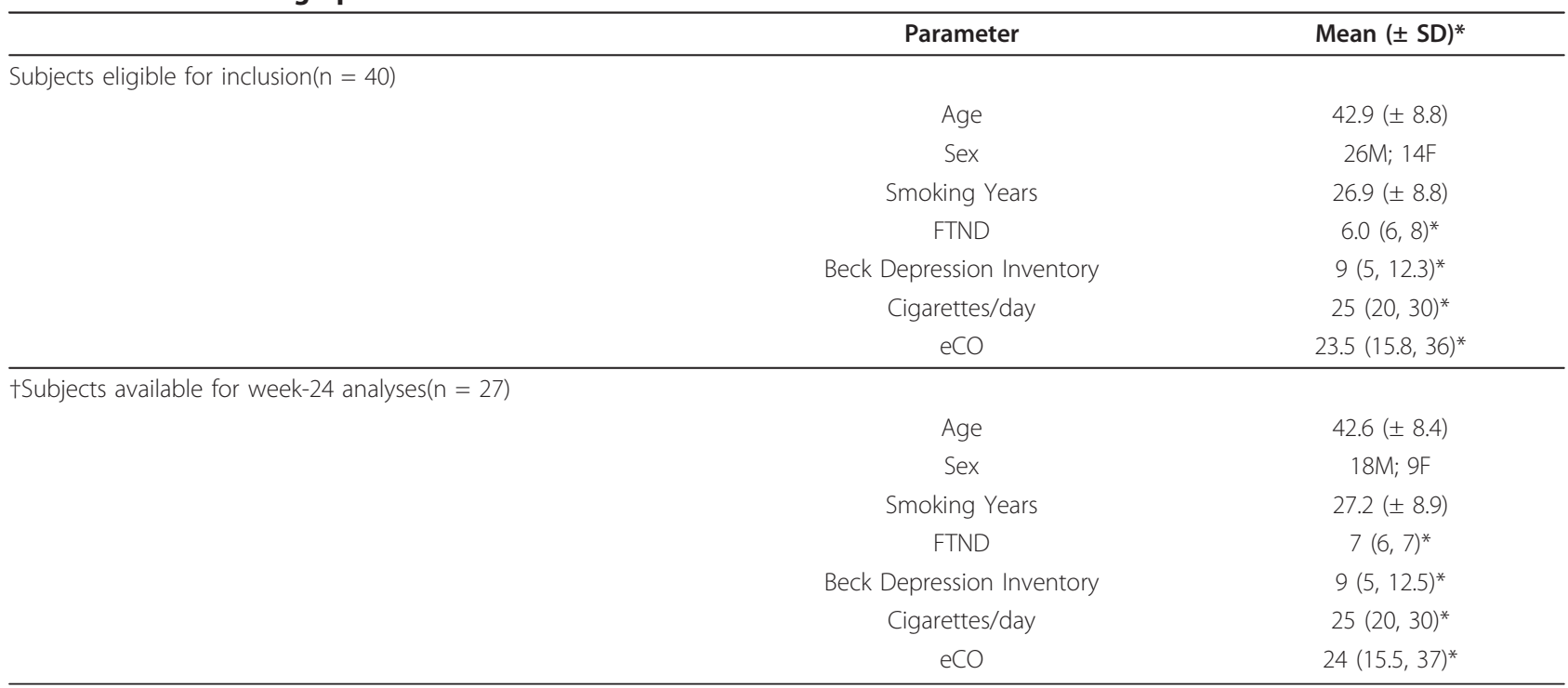

*Non-parametric data expressed as median (IQR).

† Subjects excluding those lost-to-follow-up.

Abbreviations: SD - Standard Deviation; M - Male; F - Female; FTND - Fagerstrom Test of Nicotine Dependence; eCO - exhaled carbon monoxide; IQR interquartile range. 
Table 2 Subject Parameter Outcomes Following 24 Weeks of Electronic Cigarette Use

\begin{tabular}{|c|c|c|c|}
\hline Parameter & AT BASELINE & $\begin{array}{l}\text { AT 24-Weeks } \\
\text { Post E-Cigarette }\end{array}$ & $p$ valuef \\
\hline \multicolumn{4}{|c|}{ Sustained $50 \%$ (excluding quitters) reduction in cigarette smoking $(n=13)$} \\
\hline Age & $40.1( \pm 7.7) \dagger$ & $6(5,6)^{*}$ & $<0.001$ \\
\hline Sex & $8 \mathrm{M} ; 5 \mathrm{~F}$ & $8(6,11)^{*}$ & 0.001 \\
\hline Smoking Years & $24.5( \pm 8.7) \dagger$ & & \\
\hline Cigarettes/day & $25(20,30)^{*}$ & & \\
\hline eCO & $18(14,33)^{*}$ & & \\
\hline \multicolumn{4}{|c|}{ Sustained $80 \%$ (excluding quitters) reduction in cigarette smoking $(n=5)$} \\
\hline Age & $40.6( \pm 10.4) \dagger$ & $3(3,6)^{*}$ & 0.043 \\
\hline Sex & $4 \mathrm{M} ; 1 \mathrm{~F}$ & $6(4,10)^{*}$ & 0.042 \\
\hline Smoking Years & $25.4( \pm 11.8) \dagger$ & & \\
\hline Cigarettes/day & $30(25,35)^{*}$ & & \\
\hline eCO & $15(14,44)^{*}$ & & \\
\hline \multicolumn{4}{|c|}{ Sustained 100\% (quitters) reduction in cigarette smoking $(n=9)$} \\
\hline Age & $44.7( \pm 9.3)+$ & $0(0,0)^{*}$ & 0.008 \\
\hline Sex & $8 \mathrm{M} ; 1 \mathrm{~F}$ & $3(2,3)^{*}$ & 0.008 \\
\hline Smoking Years & $29( \pm 9.6) \dagger$ & & \\
\hline Cigarettes/day & $25(23,30)^{*}$ & & \\
\hline eCO & $31(23,41)^{*}$ & & \\
\hline \multicolumn{4}{|c|}{ Sustained $>50 \%$ (including quitters) reduction in cigarette smoking $(n=22)$} \\
\hline Age & $42( \pm 8.5) \dagger$ & $3(0,6)^{*}$ & $<0.001$ \\
\hline Sex & $16 \mathrm{M} ; 6 \mathrm{~F}$ & $5.5(3,9.5)^{*}$ & $<0.001$ \\
\hline Smoking Years & $26.3( \pm 9.1) \dagger$ & & \\
\hline Cigarettes/day & $25(20,30)^{*}$ & & \\
\hline eCO & $27(15.5,37.5)^{*}$ & & \\
\hline \multicolumn{4}{|c|}{ Smoking Failure (< 50\% smoking reduction) $(n=5)$} \\
\hline Age & $45.6( \pm 7.9) \dagger$ & $20(20,20)^{*}$ & 0.157 \\
\hline Sex & $2 \mathrm{M} ; 3 \mathrm{~F}$ & $28(17,31)^{*}$ & 0.892 \\
\hline Smoking Years & $31.2( \pm 7)+$ & & \\
\hline Cigarettes/day & $25(20,25)^{*}$ & & \\
\hline $\mathrm{eCO}$ & $18(16,32)^{*}$ & & \\
\hline
\end{tabular}

Abbreviations: SD - Standard Deviation; M - Male; F - Female; eCO - exhaled carbon monoxide.

$\neq \mathrm{p}$ value - within group Wilcoxon Signed Rank Test.

† Parametric data expressed as mean $( \pm \mathrm{SD})$.

${ }^{*}$ Non-parametric data expressed as median (interquartile range(IQR)).

\section{Product Use}

Details of mean cartridge use throughout the study is shown in Figure 5. The reported number of cartridges/ day used by our study participants was dissimilar, ranging from a maximum of 4 cartridges/day (as per manufacturer's recommendation) to a minimum of 0 cartridges/day ('zero' was recorded in the study diary, when the same cartridge was used for more than 24 hours). For the whole group $(n=27)$, a mean $( \pm$ SD) $2.0( \pm 1.4)$ cartridges/day was used throughout the study. The number of cartridges/day used was slightly higher when these summary statistics were computed with the exclusion of the eight study failures; the value increasing to a mean $( \pm \mathrm{SD})$ of $2.2( \pm 1.3)$ cartridges/ day. Correlation between the number of cartridges/day and smoking reduction in those participants with sustained 50\% reduction in smoking was not significant (Rho -0.003; p = 0.988). Likewise, the correlation between the number of cartridges/day, and combined sustained 50\% reduction and smoking abstinence was also non-significant (Rho -0.185; $\mathrm{p}=0.546$ ).

\section{Adverse Events}

The most frequently reported adverse events were mouth irritation $(20,6 \%)$, throat irritation $(32,4 \%)$, and dry cough $(32,4 \%)$ (Table 3$)$. These events were most commonly reported at the beginning of the study and appeared to wane spontaneously by study visit 5 . Remarkably, side effects commonly recorded during smoking cessation trials with drugs for nicotine dependence were absent (i.e. depression, anxiety, insomnia, irritability, hunger, constipation were not reported). 


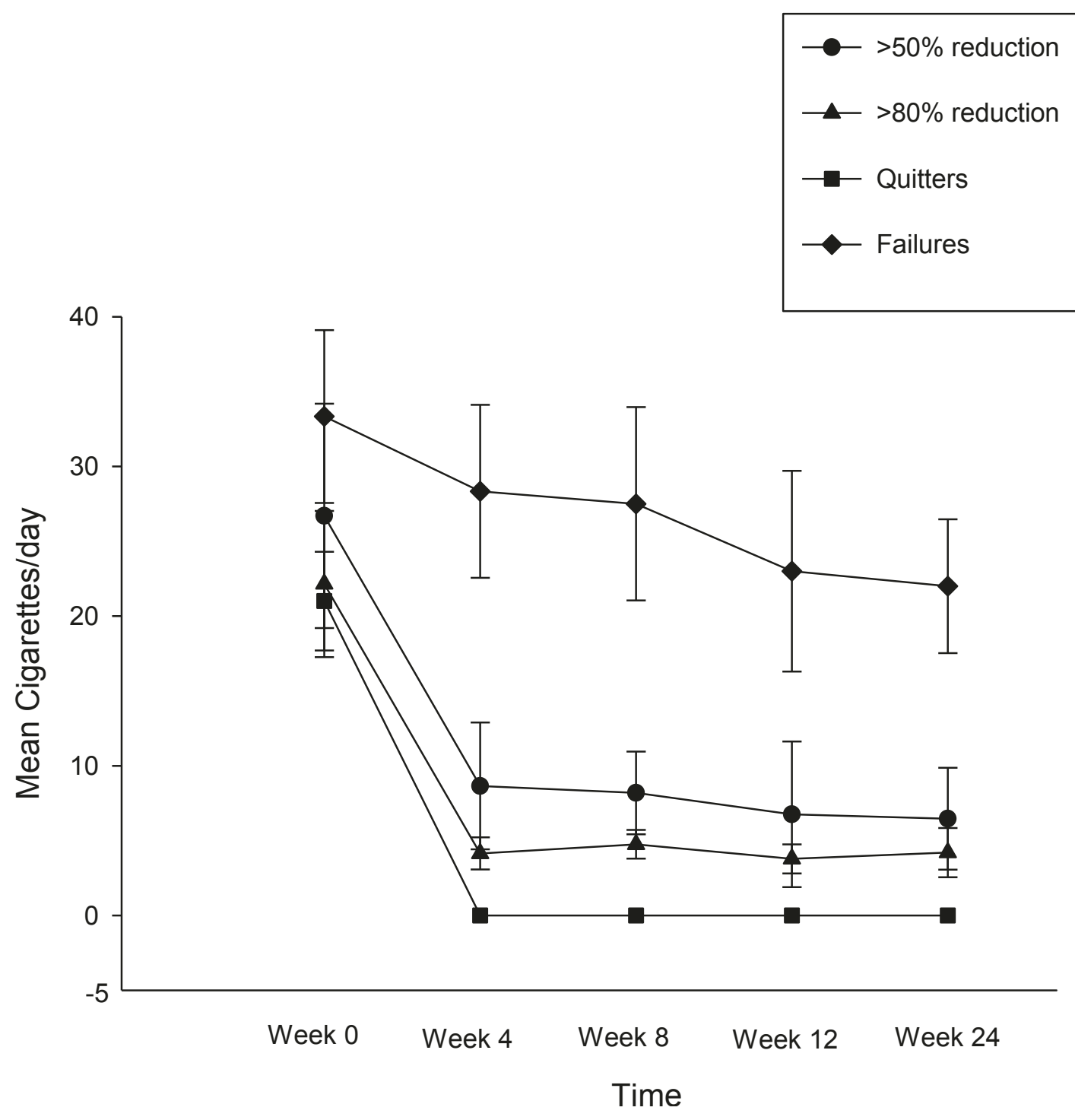

Figure 3 Changes in the mean ( \pm SD) cigarette use for each study subgroups throughout the study.

Moreover, no serious adverse events (i.e. events requiring unscheduled visit to the family practitioner or hospitalisation) occurred during the study.

\section{Product Preferences}

The 'Categoria' e-Cigarette rated scores well above the mean for satisfaction and for helpfulness (enabling them to refrain from smoking), their mean $( \pm$ SD) VAS values being $6.3( \pm 2.5)$ and $7.5( \pm 2.7)$ respectively. Moreover, it was observed that participants would enthusiastically recommend the e-Cigarette to friends or relatives who wanted to stop/reduce smoking, the mean $( \pm$ SD) VAS value being 8.0 ( \pm 3.4$)$. Predictably, the e-Cigarette rated even higher scores when these summary statistics were computed with the exclusion of the study failures $(\mathrm{n}=$ $8)$. On the contrary, the perception and acceptance of the product by those who failed to remain abstinent or to reduce smoking $(n=5)$ was poor; the mean $( \pm S D)$ VAS values for satisfaction and for helpfulness being 2.2 $( \pm 0.8)$ and $2.5( \pm 1.0)$, respectively. As expected, these individuals were unlikely to recommend the 'Categoria' e-Cigarette to friends or relatives; the mean $( \pm$ SD) VAS value being $2.3( \pm 1.2)$.

Among the most positive features of e-Cigarettes were the pleasure of inhalation and exhalation of the vapour. Other positive features mentioned included cleaner and fresher breath, absence of odours in clothing and hair. Although the overall participants' perception and acceptance of the product was good, its ease of use could be improved and technical defects reduced. During the course of the study, five study participants could not use the product as recommended and had to be retrained 


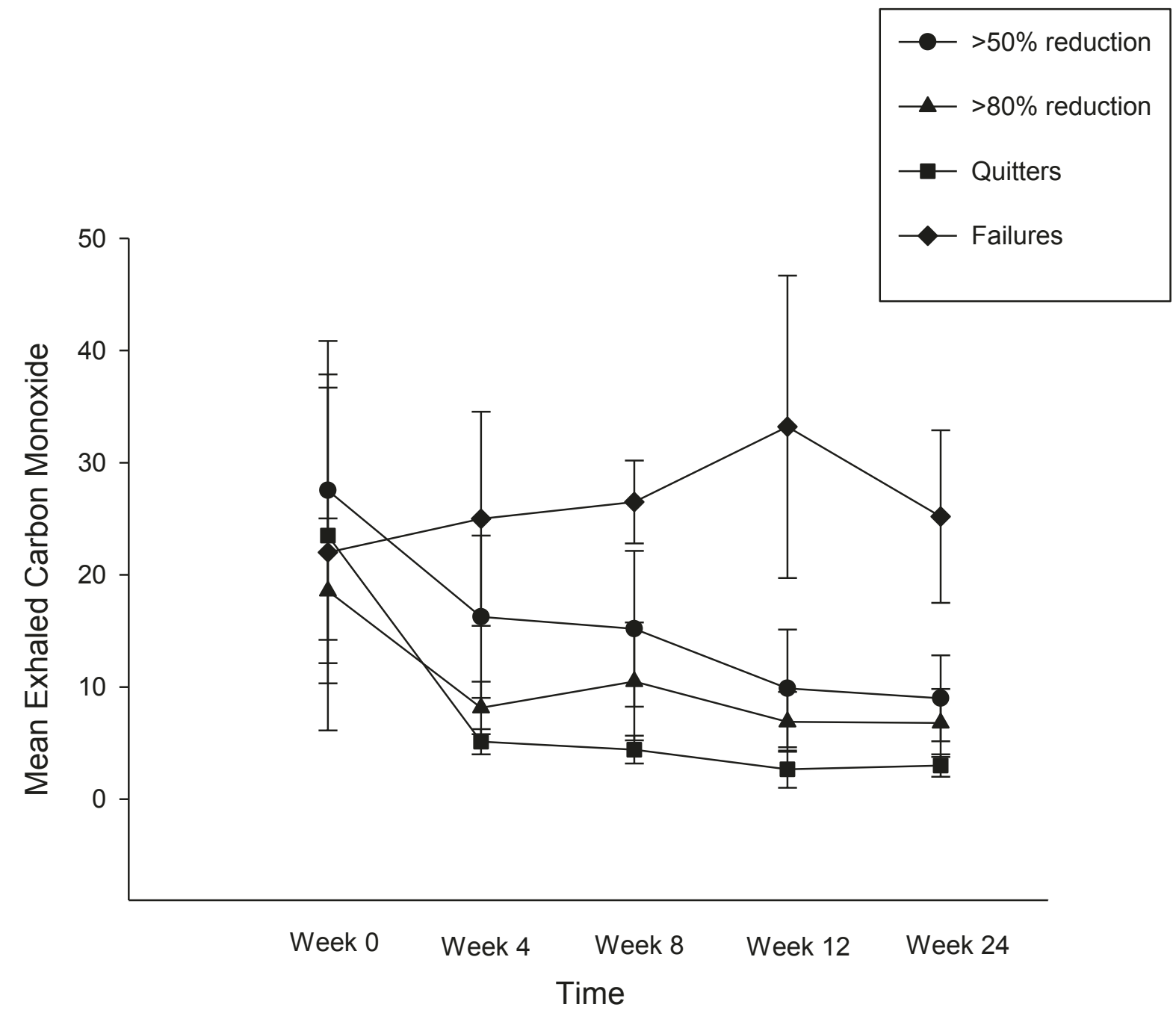

Figure 4 Changes in the mean $( \pm S D$ ) eCO levels for each study subgroups throughout the study.

within 72 hours. Three participants reported that the device often failed to produce mist when puffed (three atomizers had to be substituted). Another two were given a faulty charger (chargers were immediately replaced). According to study participants, perception and acceptance of the product could be improved by increasing manufacturing standards, by providing a recharge lasting at least 24 hours, by reducing the weight of the device and by substituting the hard plastic mouthpiece.

\section{Discussion}

In this pilot study, we have shown for the first time that substantial and objective modifications in the smoking habits may occur in smokers using e-Cigarettes, with significant smoking reduction and smoking abstinence and no apparent increase in withdrawal symptoms. Participants were not only enthusiastic about using the e-
Cigarette, but the majority (67.5\%) were also able to adhere to the program and to return for the final follow-up visit at week-24 with an overall quit rate of $22.5 \%$. Moreover, at least $50 \%$ reduction in cigarette smoking was observed in $32.5 \%$ of participants. Overall, combined reduction and smoking abstinence was shown in $55 \%$ of participants. These preliminary findings are of great significance in view of the fact that all smokers in the study were, by inclusion criteria, not interested in quitting. Although not directly comparable with classic cessation and/or reduction studies with other pharmaceutical products because of its design (the present study is not an ordinary cessation study), the results of our study are in general accordance with the findings published in the medical literature [17].

The large magnitude of this effect suggests the eCigarette strongly suppressed cigarette use. However, no correlations were observed between the number of 


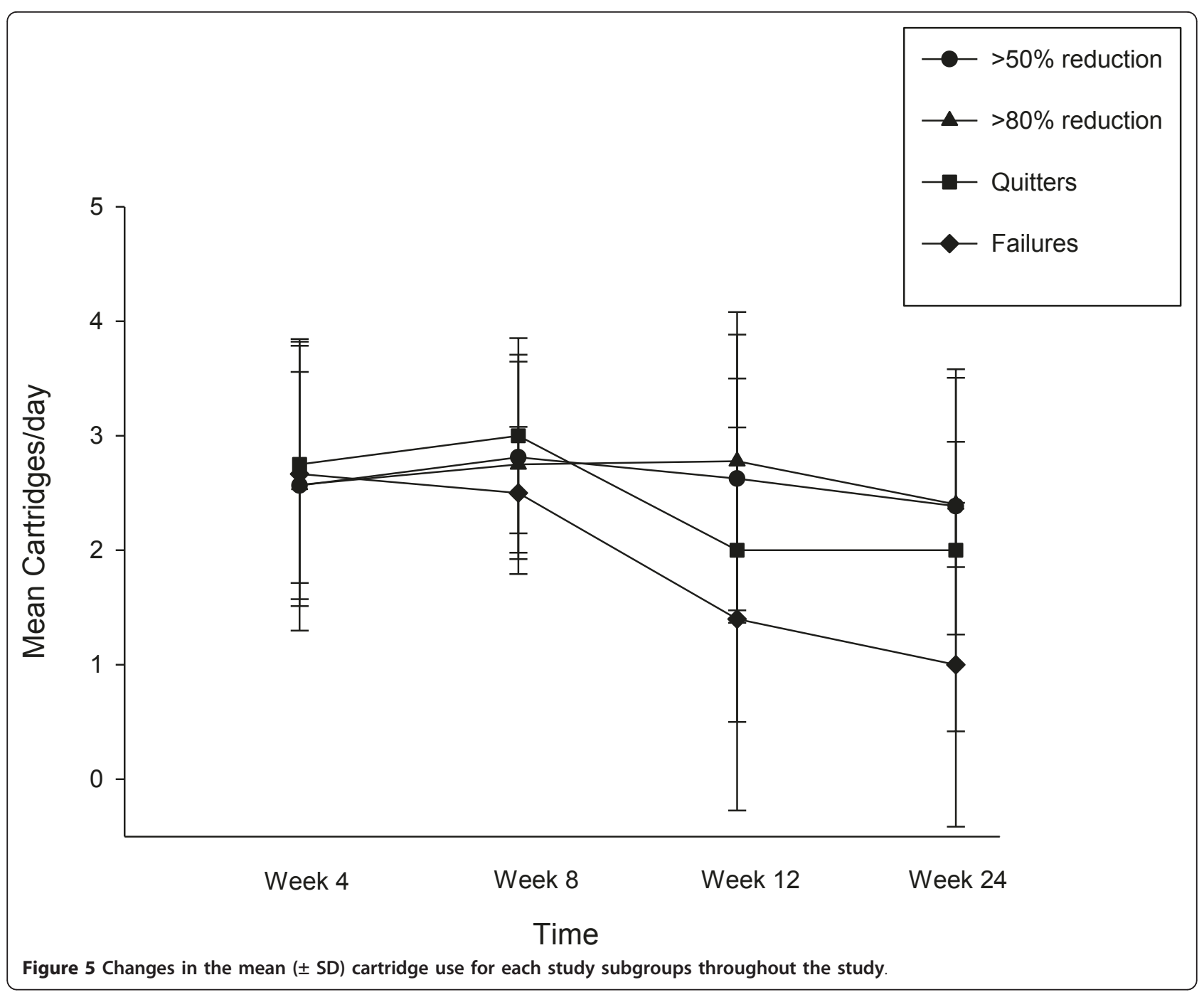

Table 3 Adverse events reported by participants who completed all study visits

\begin{tabular}{|c|c|c|c|c|}
\hline \multirow[t]{2}{*}{ Adverse Event } & \multicolumn{4}{|c|}{ Study Visits } \\
\hline & $\begin{array}{l}\text { 4-week } \\
\text { n/n (\%) }\end{array}$ & $\begin{array}{l}\text { 8-week } \\
\text { n/n (\%) }\end{array}$ & $\begin{array}{l}\text { 12-week } \\
\text { n/n (\%) }\end{array}$ & $\begin{array}{c}\text { 24-week } \\
\text { n/n (\%) }\end{array}$ \\
\hline $\begin{array}{l}\text { Throat } \\
\text { irritation* }\end{array}$ & $\begin{array}{c}11 / 34 \\
(32,4 \%) \\
\end{array}$ & $\begin{array}{c}5 / 32 \\
(15,6 \%) \\
\end{array}$ & $\begin{array}{c}5 / 30 \\
(16,7 \%) \\
\end{array}$ & $\begin{array}{c}4 / 27 \\
(14,8 \%) \\
\end{array}$ \\
\hline $\begin{array}{l}\text { Mouth } \\
\text { Irritation* }\end{array}$ & $7 / 34(20,6 \%)$ & $\begin{array}{c}4 / 32 \\
(12,5 \%)\end{array}$ & $\begin{array}{c}3 / 30 \\
(10,0 \%)\end{array}$ & $2 / 27(7,4 \%)$ \\
\hline Sore Throat & $4 / 34(11,8 \%)$ & $1 / 32(3,1 \%)$ & $1 / 30(3,3 \%)$ & $0 / 27(0,0 \%)$ \\
\hline Dry cough & $\begin{array}{c}11 / 34 \\
(32,4 \%)\end{array}$ & $\begin{array}{c}6 / 32 \\
(18,8 \%)\end{array}$ & $\begin{array}{c}3 / 30 \\
(10,0 \%)\end{array}$ & $\begin{array}{c}3 / 27 \\
(11,1 \%)\end{array}$ \\
\hline Dry mouth & $3 / 34(8,8 \%)$ & $1 / 32(3,1 \%)$ & $1 / 30(3,3 \%)$ & $1 / 27(3,7 \%)$ \\
\hline Mouth ulcers & $1 / 34(2,9 \%)$ & $1 / 32(3,1 \%)$ & $1 / 30(3,3 \%)$ & $0 / 27(0,0 \%)$ \\
\hline Dizziness $^{\S}$ & $5 / 34(14,7 \%)$ & $2 / 32(6,3 \%)$ & $2 / 30(6,7 \%)$ & $1 / 27(3,7 \%)$ \\
\hline Headache & $4 / 34(11,8 \%)$ & $2 / 32(6,3 \%)$ & $2 / 30(6,7 \%)$ & $1 / 27(3,7 \%)$ \\
\hline Nausea & $5 / 34(14,7 \%)$ & $2 / 32(6,3 \%)$ & $1 / 30(3,3 \%)$ & $1 / 27(3,7 \%)$ \\
\hline
\end{tabular}

* Throat and mouth irritation were described either as tickling, itching, or burning sensation

${ }^{\S}$ Dizziness, was also used to mean vertigo and light-headedness. nicotine cartridges/day used and the level of smoking reduction. This is not unexpected, in view of the powerful interaction between physical and behavioural dependence of smoking $[18,19]$ and the modest increases in blood nicotine levels measured after the use of this type of devices [20]. Therefore, it is unlikely that the observed positive effect of the e-Cigarette is due to nicotine delivery. Rather, the strong suppression of smoking in association with the absence of correlation between cartridges use and level of smoking reduction, suggests that the positive effect of the e-Cigarette may be also due to its capacity to provide a coping mechanism for conditioned smoking cues by replacing some of the rituals associated with smoking gestures (e.g. hand-tomouth action of smoking). In agreement with this, we have recently demonstrated that nicotine free inhalators can only improve quit rates in those smokers for whom handling and manipulation of their cigarette played an important role in their ritual of smoking [21]. 
Although dry cough and mouth ulcers can be associated with withdrawal effects, typical withdrawal symptoms of smoking cessation trials with drugs for nicotine dependence were not reported during the course of the study. It is possible that the e-Cigarette by providing a coping mechanism for conditioned smoking cues could mitigate withdrawal symptoms associated with smoking reduction and smoking abstinence. In contrast from other ENDDs such as Eclipse (which is known to generate substantial level of eCO) [22], e-Cigarettes use does not lead to increased eCO levels [12]. In the present study, the smoking reduction with 'Categoria' e-Cigarette use was associated to a substantial decrease in the level of eCO. The most frequent adverse events were mouth irritation, throat irritation and dry cough, but all appeared to wane spontaneously with time. These are likely to be secondary to exposure to propylene glycol mist generated by the e-Cigarette's atomizer. Propylene glycol is a low toxicity compound widely used as a food additive and in pharmaceutical preparations. Exposure to propylene glycol mist may occur from smoke generators in discotheques, theatres, and aviation emergency training and is known to cause ocular, mouth, throat, upper airway irritation and cough [23,24]. Dizziness was often reported by participants at the beginning of the study and can be brought about by the hyperventilation associated to the greater puffing time with the e-Cigarette. Alternatively, the dizziness as well as other reported adverse events such as nausea and headaches may be due to nicotine overuse. The substantial reduction in the frequency of dizziness observed by the end of the study may be due to the improved familiarisation with the puffing technique and/or to the overall reduction in nicotine use. Therefore, the 'Categoria"' e-Cigarette can be seen as a safe way to smoke although larger and longer studies will be required for a full assessment of its adverse events.

The 'Categoria' e-Cigarette rated high scores for a range of subjective ratings of user preferences suggesting that the product was functioning as an adequate cigarette substitute. Hence, participants were more likely to recommend the e-Cigarette to friends or relatives. Conversely, as would be expected the perception and acceptance of the product by those who failed to remain abstinent or to reduce smoking was poor and these individuals were unlikely to recommend the e-Cigarette. We cannot exclude that technical problems (particularly those who went unreported) and difficulty of use (it takes time to familiarize with the puffing technique) could have affected the number of lost to follow-up and failures. Although the overall participants' perception and acceptance of the product was good, its ease of use could be improved. Technical defects could be reduced by increasing manufacturing standards, providing a recharge lasting at least 24 hours, reducing the weight of the device and substituting the hard plastic mouthpiece. These latter two suggestions would improve device acceptability for certain common rituals of cigarette smoking, e.g. keeping the cigarette between lips.

Harm-reduction strategies are aimed at reducing the adverse health effects of tobacco use in individuals unable or unwilling to quit. Reducing the number of cig/day is one of several kinds of harm reduction strategies [25]. It is uncertain whether substantial smoking reduction in smokers using the e-Cigarette will translate in health benefits, but a number of studies have analyzed the ability of smoking reduction to lower health risks and have reported some reductions in cardiovascular risk factors and lung cancer mortality [26-28]. Moreover, reduction in cigarette smoking by e-Cigarette may well increase motivation to quit as indicated by a substantial body of evidence showing that gradually cutting down smoking can increase subsequent smoking cessation among smokers [15,29-32]. While not the treatment of choice, reduced smoking strategies might be considered for recalcitrant smokers unwilling to quit, as in the case of our study population.

There are some limitations in our study. Firstly, this was a small uncontrolled study, hence the results observed may be due to a chance finding and not to a true effect; consequently the results should be interpreted with caution. However, it would have been quite problematic to have a placebo arm in such a study. Secondly, $32.5 \%$ of the participants failed to attend their final follow-up visit, but this is not unexpected in a smoking cessation study. Thirdly, because of its unusual design (smokers not willing to quit, e-Cigarettes were used throughout the entire study period) this is not an ordinary cessation study and therefore direct comparison with other smoking cessation products cannot be made. Fourthly, failure to complete the study and smoking cessation failures could be due to occurrence of technical defects for the e-Cigarette. However, this could not be assessed with confidence in the present study. Lastly, assessment of withdrawal symptoms in our study was not rigorous. Withdrawal was assessed at each visit by simply asking about the presence/absence of irritability, restlessness, difficulty concentrating, increased appetite/weight gain, depression or insomnia. It is likely that this way of collecting information is liable to recall bias. Therefore, the reported lack of withdrawal symptoms in the study participants should be considered with caution.

\section{Conclusions}

Current smoking cessation interventions can increase the chance of quitting in committed smokers who are already motivated and prepared to stop smoking [33], 
but a broader range of interventions are needed in order to bring more smokers into treatment and increase the numbers who are motivated to make quit attempts. Although not formally regulated as a pharmaceutical product, the e-Cigarette can help smokers to remain abstinent or reduce their cigarette consumption. By replacing tobacco cigarettes, the e-cigarette can only save lives.

Here we show for the first time that e-Cigarettes can substantially decrease cigarette consumption without causing significant side effects in smokers not intending to quit. However, large and carefully conducted RCTs will be required before a definite answer about the efficacy and safety of these devices can be formulated. Some of these trials are now in progress in Italy [34-36] and New Zealand [37] and hopefully they will be able to confirm and expand the preliminary observations reported in the present article.

\section{Abbreviations}

e-Cigarette: Electronic-Cigarette; ENDD: Electronic Nicotine Delivery Device; Cig/day: Cigarettes smoked per day; BP: Blood pressure; $\mathrm{mmHg}$ : millimetres of mercury; FTND: Fagerstrom Test of Nicotine Dependence; BDI: Beck's Depression Inventory; eCO: exhaled carbon monoxide; mg: milligrams; Cartridges/day: cartridges used per day; VAS: Visual Analogue Score; ppm: parts per million; Pack/yrs: pack-years; SD: standard deviation; IQR: interquartile range

\section{Acknowledgements}

We wish to thank Arbi Group Srl (Milano, Italy) for the free supplies of 'Categoria' e-Cigarette kits and nicotine cartridges as well as their support. We would also like to thank the study participants for all their time and effort and LIAF (Lega Italiana AntiFumo) for the collaboration.

\section{Author details}

${ }^{1}$ Centro per la Prevenzione e Cura del Tabagismo (CPCT), Azienda Ospedaliero-Universitaria "Policlinico-Vittorio Emanuele", Università di Catania, Catania, Italy. ${ }^{2}$ Institute of Internal Medicine, S. Marta Hospital, Azienda Ospedaliero-Universitaria "Policlinico-Vittorio Emanuele", Università di Catania, Catania, Italy. ${ }^{3} I I R$ Division, School of Medicine, University of Southampton, Southampton General Hospital, Southampton SO16 6YD, UK.

\section{Authors' contributions}

RP: Principal investigator, protocol design, interpretation of the data, writing of the ms; PC: conduction of the study, interpretation of the data, writing of the ms; JBM: statistical analyses, interpretation of the data, writing of the ms; GP: recruiting of patients, conduction of the study, writing of the ms; DC: recruiting of patients, conduction of the study; CR: protocol design, interpretation of the data, writing of the ms. All authors have read and approved the final manuscript.

\section{Competing interests}

None of the authors have any competing interests to declare, but RP has received lecture fees from Pfizer and, from Feb 2011, he has been serving as a consultant for Arbi Group Srl.Arbi Group Srl (Milano, Italy), the manufacturer of the e-Cigarette supplied the product, and unrestricted technical and customer support. They were not involved in the study design, running of the study or analysis and presentation of the data.

Received: 25 November 2010 Accepted: 11 October 2011 Published: 11 October 2011

\section{References}

1. Tobacco or Health:a Global Status Report. Geneva; 1997.
2. Doll $R$, Peto $R$, Boreham J, Sutherland I: Mortality in relation to smoking: 50 years' observations on male British doctors. BMJ 2004, 328(7455):1519.

3. Boyle P, Gray N, Henningfield J, Seffrin J, Zatonski W: Tobacco and Public Health: Science and Policy. Oxford: Oxford University Press; 2004

4. The health benefits of smoking cessation. Edited by: Services UDoHaH: USA, US Department of Health and Human Services, Public Health Service, Centers for Disease Control, Center for Chronic Disease Prevention and Health Promotion, Office on Smoking and Health 1990.

5. Lightwood JM, Glantz SA: Short-term economic and health benefits of smoking cessation: myocardial infarction and stroke. Circulation 1997, 96(4):1089-1096.

6. Fiore MC, Jaen CR, Baker TB, Bailey WC, Benowitz NL, Curry SJ, Dorfman SF, et al: Treating tobacco use and dependence. Clinical practice guidelines 2008 Update.Edited by: Services UDoHaH. Rockville, MD: Public Health Service 2008.

7. Hughes JR, Keely J, Naud S: Shape of the relapse curve and long-term abstinence among untreated smokers. Addiction 2004, 99(1):29-38.

8. Casella G, Caponnetto P, Polosa R: Therapeutic advances in the treatment of nicotine addiction: Present and Future. Ther Adv Chronic Dis 2010, 1(3):95-106.

9. Hon L: A non-smokable electronic spray cigarette (CA 2518174) \{Patent notice\}.Edited by: Record CPO 133:2005.

10. Zezima K: Cigarettes without smoke or regulation. New York Times. New York; 2009.

11. Etter JF: Electronic cigarettes: a survey of users. BMC Public Health; 2010:10:231.

12. Vansickel AR, Cobb CO, Weaver MF, Eissenberg TE: A clinical laboratory model for evaluating the acute effects of electronic "cigarettes": nicotine delivery profile and cardiovascular and subjective effects. Cancer Epidemiol Biomarkers Prev 2010, 19(8):1945-1953.

13. Fagerstrom $\mathrm{KO}$, Schneider NG: Measuring nicotine dependence: a review of the Fagerstrom Tolerance Questionnaire. J Behav Med 1989, 12(2):159-182.

14. Beck A, Ward C, Mendelson M, Mock J, Erbaugh J: Manual for the Beck Depression Inventory. New York Harcourt Brace Jovanovich; 1987.

15. Bolliger CT, Zellweger JP, Danielsson T, van Biljon X, Robidou A, Westin A, Perruchoud AP, Sawe U: Smoking reduction with oral nicotine inhalers: double blind, randomised clinical trial of efficacy and safety. BMJ 2000, 321(7257):329-333.

16. Polosa R, Russo C, Di Maria A, Arcidiacono G, Piccillo G: Smoking cessation and reduction through e-mail counselling. Respir Med 2008, 102(4):632.

17. Smith SS, McCarthy DE, Japuntich SJ, Christiansen B, Piper ME, Jorenby DE, Fraser DL, Fiore MC, Baker TB, Jackson TC: Comparative effectiveness of 5 smoking cessation pharmacotherapies in primary care clinics. Arch Intern Med 2009, 169(22):2148-2155.

18. Laurier E, McKie L, Goodwin N: Daily and life-course contexts of smoking. Sociol Health IIIn 2000, 22:289-309.

19. Jarvis MJ: Why people smoke. BMJ 2004, 328(7434):277-279.

20. Bullen C, McRobbie H, Thornley S, Glover M, Lin R, Laugesen M: Effect of an electronic nicotine delivery device (e cigarette) on desire to smoke and withdrawal, user preferences and nicotine delivery: randomised cross-over trial. Tob Control 2010, 19(2):98-103.

21. Caponnetto P, Cibella F, Mancuso S, Campagna D, Arcidiacono G, Polosa R: Effect of a nicotine free inhalator as part of a smoking cessation program. Eur Respir J 2011 May 12. [Epub ahead of Print].

22. Fagerstrom KO, Hughes JR, Rasmussen T, Callas PW: Randomised trial investigating effect of a novel nicotine delivery device (Eclipse) and a nicotine oral inhaler on smoking behaviour, nicotine and carbon monoxide exposure, and motivation to quit. Tob Control 2000, 9(3):327-333.

23. Wieslander G, Norback D, Lindgren T: Experimental exposure to propylene glycol mist in aviation emergency training: acute ocular and respiratory effects. Occup Environ Med 2001, 58(10):649-655.

24. Varughese $S$, Teschke K, Brauer M, Chow Y, van Netten C, Kennedy SM: Effects of theatrical smokes and fogs on respiratory health in the entertainment industry. Am J Ind Med 2005, 47(5):411-418.

25. McNeill A: Harm reduction. BMJ 2004, 328(7444):885-887.

26. Bolliger CT, Zellweger JP, Danielsson T, van Biljon X, Robidou A, Westin A, Perruchoud AP, Sawe U: Influence of long-term smoking reduction on health risk markers and quality of life. Nicotine Tob Res 2002, 4(4):433-439. 
27. Hatsukami DK, Kotlyar M, Allen S, Jensen J, Li S, Le C, Murphy S: Effects of cigarette reduction on cardiovascular risk factors and subjective measures. Chest 2005, 128(4):2528-2537.

28. Godtfredsen NS, Prescott E, Osler M: Effect of smoking reduction on lung cancer risk. JAMA 2005, 294(12):1505-1510.

29. Hughes JR, Carpenter MJ: The feasibility of smoking reduction: an update. Addiction 2005, 100(8):1074-1089.

30. Wennike P, Danielsson T, Landfeldt B, Westin A, Tonnesen P: Smoking reduction promotes smoking cessation: results from a double blind, randomized, placebo-controlled trial of nicotine gum with 2-year followup. Addiction 2003, 98(10):1395-1402.

31. Rennard SI, Glover ED, Leischow S, Daughton DM, Glover PN, Muramoto M, Franzon M, Danielsson T, Landfeldt B, Westin A: Efficacy of the nicotine inhaler in smoking reduction: A double-blind, randomized trial. Nicotine Tob Res 2006, 8(4):555-564.

32. Walker N, Bullen C, McRobbie H: Reduced-nicotine content cigarettes: Is there potential to aid smoking cessation? Nicotine Tob Res 2009, 11(11):1274-1279.

33. Polosa R, Benowitz NL: Treatment of nicotine addiction: present therapeutic options and pipeline developments. Trends Pharmacol Sci 2011, 32(5):281-9.

34. [http://clinicaltrials.gov/ct2/show/NCT01164072?term=electronic +cigarette\&rank = 1].

35. [http://clinicaltrials.gov/ct2/show/NCT01194583?term=polosa\&rank = 2]

36. [http://clinicaltrials.gov/ct2/show/NCT01188239?term=polosa\&rank $=3$ ] .

37. [http://www.anzctr.org.au/trial_view.aspx?!D = 336091].

\section{Pre-publication history}

The pre-publication history for this paper can be accessed here: http://www.biomedcentral.com/1471-2458/11/786/prepub

\section{doi:10.1186/1471-2458-11-786}

Cite this article as: Polosa et al: Effect of an electronic nicotine delivery device (e-Cigarette) on smoking reduction and cessation: a prospective 6-month pilot study. BMC Public Health 2011 11:786.

\section{Submit your next manuscript to BioMed Central and take full advantage of:}

- Convenient online submission

- Thorough peer review

- No space constraints or color figure charges

- Immediate publication on acceptance

- Inclusion in PubMed, CAS, Scopus and Google Scholar

- Research which is freely available for redistribution 